\title{
MODELAGEM AMBIENTAL NA ANÁLISE DA DESERTIFICAÇÃO NO ESTADO DA BAHIA: UMA ABORDAGEM NO CONTEXTO AMBIENTAL DE CANUDOS E JEREMOABO
}

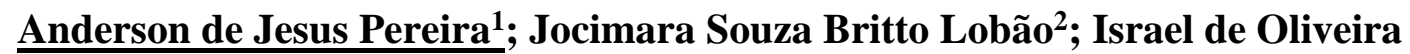 \\ Junior $^{3}$ \\ 1. Bolsista PROBIC/UEFS, Graduando em Agronomia, Universidade Estadual de Feira de Santana; e-mail: \\ agroandersonn@gmail.com \\ 2. Orientadora, Departamento de Ciências Humanas e Filosofia, Universidade Estadual de Feira de Santana; e-mail: \\ juci.lobao@gmail.com \\ 3. Participante do Grupo de Pesquisa CNPq Natureza, Sociedade e Ordenamento Territorial (UEFS); Departamento \\ de Ciências Humanas, Campus IV, Universidade Estadual da Bahia; e-mail: iojjunior@gmail.com
}

PALAVRAS-CHAVE: degradação ambiental; semiárido; erosão.

\section{INTRODUÇÃO}

O processo de degradação das terras secas tem origem remota e a ele está associada a decadência de civilizações antigas, como os sumérios e babilônios (HARE et al., 1992).

No entanto, a aplicação do termo desertificação nos meios técnicos e científicos decorreu no ano de 1949, quando o francês Aubreville o associou aos danos ambientais ocasionados pela apropriação humana dos recursos ambientais das regiões secas da África. Nos anos subsequentes, prosseguiram os debates em nível mundial a respeito da problemática e, durante a II Conferência das Nações Unidas sobre Meio Ambiente e Desenvolvimento Humano (Rio-92), realizada na cidade de Rio de Janeiro (RJ), em 1992, conceituaram o processo como: "degradação da terra em regiões áridas, semiáridas e subúmidas secas, resultante de diversos fatores, entre eles a variação climática e as atividades humanas" (UNITED NATIONS, s.p, 1997).

Os processos de degradação incluem alterações físicas, químicas e biológicas nas propriedades do solo e nos processos edáficos, que conduzem a uma redução da qualidade do solo como recurso (GOMEZ \& BERMÚDEZ, 2010). A teia de relações processuais da erosão é considerada uma das maiores causadoras da degradação do solo no mundo, além de estar altamente associado ao abandono de terra e o desenvolvimento da desertificação (KOSMAS et al., 2010; VALENTIN et al., 2005).

Ver-se, com isso, que o processo de erosão se encontra entre aqueles que causam problemas graves nas terras secas, principalmente quando a intensidade dele é superior à considerada normal (NASCIMENTO, 2013; HARE et al., 1992). Ela é denominada erosão acelerada a partir do momento em que gera degradação ambiental, com graves consequências, por gerar problemáticas para o meio ambiente e para o desenvolvimento das atividades humanas, tão comuns nas áreas desertificadas. Nesse contexto, em uma perspectiva de contribuir com as discussões científicas sobre o processo de degradação das terras localizadas no semiárido brasileiro, objetivou, neste estudo, mapear a vulnerabilidade ambiental dos solos à erosão nos municípios de Canudos e JeremoaboBA, para discorrer sobre elementos relacionados à desertificação.

\section{MATERIAL E MÉTODOS OU METODOLOGIA}

A área de estudo compreende os municípios de Canudos e Jeremoabo, localizados no norte do estado da Bahia, que integram a área suscetível à desertificação (ASD) do Brasil; neles há indícios de vulnerabilidade à desertificação, como apontaram alguns estudos (AB'SABER, 1977; OLIVEIRA JUNIOR, 2014; LOBÃO \& SILVA, 2013); as secas ocorrem com frequência entre 61\% e 80\% (CARVALHO, 1973), não há excedente hídrico em nenhum mês e o clima é caracterizado pelo constante déficit hídrico, em cerca de 950mm (SEI, 1999), demostrando a severidade climática. 
A execução do estudo baseou-se, inicialmente, em uma revisão bibliográfica sobre desertificação (BRASIL, 2005; GOMEZ \& BERMÚDEZ, 2010; HARE et al., 1992; MATALLO JUNIOR, 2001; UNITED NATIONS, 1997; OLIVEIRA JUNIOR, 2014, QUARANTA, 2010), modelagem de vulnerabilidade ambiental à desertificação (CREPANI et al., 2008; OLIVEIRA JUNIOR, 2014; LOBÃO \&; SILVA, 2013). Junto a etapa da revisão da literatura realizou-se a revisão cartográfica, para identificação de produtos pré-existentes e construção de banco de dados em sistema de informação geográfica (SIG), com informações relacionadas ao clima, relevo, litologia, solo, vegetação, uso da terra, de fontes secundárias (SIG-BAHIA, 2003; OLIVEIRA JUNIOR, 2014). Esses dados foram importantes para iniciar o processo a modelagem de vulnerabilidade à desertificação.

Elaborou-se mapas de variáveis do relevo, como declividade, plano de curvatura, perfil de curvatura e índice topográfico de umidade. Os dados foram extraídos do modelo digital de terreno (MDT), com resolução de 30m (NASA, 2013), a partir da aplicação de técnicas de geoprocessamento. Os dados foram integrados no SIG da pesquisa, para análise da paisagem dos municípios e configuração de cenários ambientais.

$\mathrm{Na}$ modelagem digital à erosão foram integradas variáveis litológicas, pedológicas, do relevo e de uso e cobertura da terra. Para isso, empregou-se a lógica fuzzy na integração dos planos de informações no processo da modelagem de vulnerabilidade à erosão. Cada classe dos planos de informações utilizados para a modelagem, compreendeu valores em um intervalo entre zero e um, sem restrições dos valores intermediários, sendo que os valores mais próximos de 1 refere-se ao maior nível de vulnerabilidade. A definição das classes de vulnerabilidade ambiental à erosão decorreu da sobreposição dos mapas ambientais em ambiente SIG, pela aplicação de operadores fuzzy.

No processo de análise ambiental e verificação dos produtos elaborados pelas técnicas de geoprocessamento, realizou-se estudos de campo, nos quais preencheu-se planilhas com informações ambientais e obteve-se as coordenadas geográficas para integração dos dados ao SIG da pesquisa.

\section{RESULTADOS E DISCUSSÃO}

No contexto da análise da vulnerabilidade ambiental à erosão, algumas informações ambientais possuem importância, pois influenciam diretamente nos processos de intemperismo e transporte dos materiais que formam os solos, o que encontra nas discussões sobre a hierarquia dos sistemas ambientais, conforme aponta Bertrand (1971) e Tricart (1977). Com isso, por meio da revisão da literatura, dos estudos de campo e da disponibilidade de dados ambientais, selecionou-se planos de informações para integrá-los em ambiente SIG e confeccionar a modelagem.

A partir da definição dos planos de informação, dos critérios e estabelecimento dos membros fuzzy para cada classe, realizou-se alguns testes de modelagem. Todos eles foram verificados com dados e informações obtidos em campo, numa busca de aproximá-los à realidade ambiental da área de estudo. Nesse sentido, o mais apropriado referiu ao operador gamma com expoente 7 , pois foi o que mais demonstrou qualidade em função das características ambientais encontradas nos municípios de Canudos e Jeremoabo, cujo resultado é ilustrado pela figura 1.

$\mathrm{Na}$ área de estudo, a classe de maior abrangência é a de alta susceptibilidade, distribuída em 31,06\% das terras (Figura 1). São ambientes de mudanças acentuadas de declive, relevos convexo-convergentes, em diferentes tipologias de solo e litologias.

A de severa refere-se a $1.124,03 \mathrm{~km}^{2}$, o que equivale a $17,70 \%$ da área de estudo (Figura 1); são áreas mais preocupantes frente à deterioração ambiental, por possuir fatores que 
acentuam o processo de erosão. Elas são compreendias, sobretudo, por arenitos, em declividades acentuadas e relevos de curvatura convexo-convergente. Os solos predominantes são os neossolos, onde desenvolvem a agropecuária, a caatinga parque antropizada e a caatinga arbórea e arbustiva antropizada.

A classe de baixa susceptibilidade à erosão correspondeu a $25,40 \%$ da área de estudo; conjuntamente à de média, soma $51,24 \%$ (Figura 1). Elas são mais evidenciadas nos topos dos tabuleiros do rio Vaza-Barris (Figura 1), que formam a bacia sedimentar Recôncavo-Tucano.

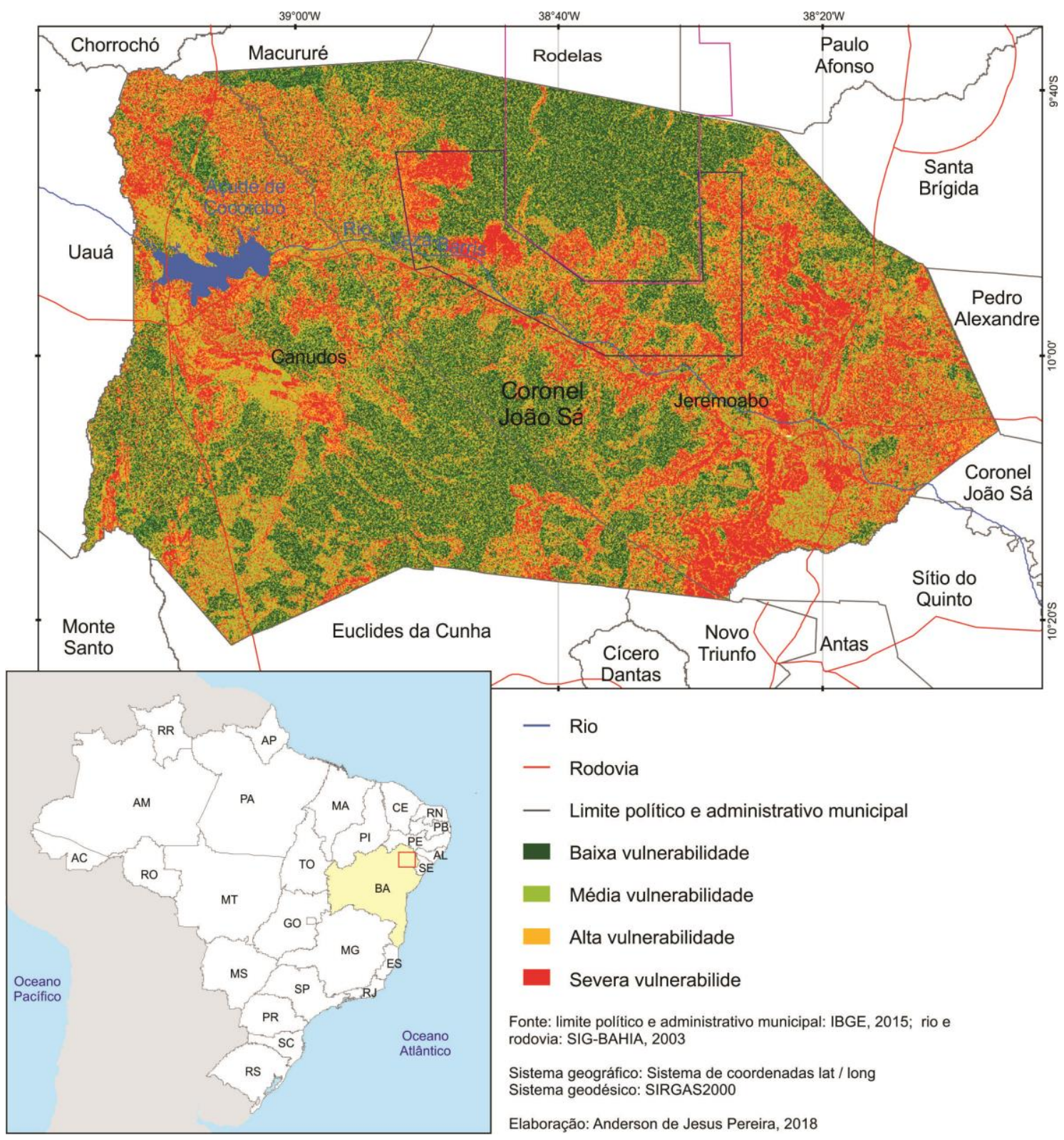

Figura 1: Vulnerabilidade ambiental à erosão em Canudos e Jeremoabo - Bahia

\section{CONSIDERAÇÕES FINAIS}

Por meio deste estudo, constatou-se a importância do geoprocessamento para a elaboração de dados e informações ambientais no contexto da desertificação. A formação de um banco de dados SIG possibilitou a análise da paisagem, a partir de dados secundários, e possibilitou a confecção de dados primários com rigor científico. A ampliação das possibilidades de obter informações sobre a vulnerabilidade à desertificação decorreu da aplicação da lógica fuzzy. O emprego e o estabelecimento dos níveis de pertencimento ao conjunto fuzzy indicaram a correspondência entre o 
modelo de vulnerabilidade ambiental à desertificação e a realidade de campo. A definição das áreas de maiores índices de vulnerabilidade teve correspondência com os ambientes de uso intenso da terra pelas atividades agropecuárias.

Identificou-se que a vulnerabilidade severa ocorre em relevos declivosos, divergentes-convergentes, com potencial de umidade muito baixo e baixo em relação ao índice topográfico de umidade, onde encontram-se os arenitos e neossolos. A realidade piora quando ocorre o desenvolvimento da agropecuária, o que foi observado, principalmente no vale do rio Vaza-Barris e nas mediações do lago de Cocorobó, o que evidencia que as práticas humanas é a causa da degradação das terras secas, que são marcadas pela fragilidade ambiental.

\section{REFERÊNCIAS}

AB'SABER, A. N. 1997. Problemática da desertificação e da savanização no Brasil intertropical. Geomorfologia. (53): 1-19.

BERTRAND, G. 1971. Paisagem e geografia física global: um esboço metodológico. Cadernos de Ciências da Terra. (13): 1-27.

BRASIL. 2005. Programa Nacional de Combate à Desertificação e Mitigação dos Efeitos da Seca-PAN-Brasil. Brasília, DF, MMA.

CARVALHO, O. 1973. Plano integrado para o combate preventivo aos efeitos das secas no Nordeste. Brasília, DF, Minter.

CREPANI, E.; MEDEIROS, J. S. PALMEIRAS A. F.; SILVA, E. F. Zoneamento Ecológico-Econômico. In: T. G. FLORENZANO (Coord.). 2008. Geomorfologia: conceitos e tecnologias atuais. São Paulo, Oficina de Textos.

GOMEZ, J. G.; BERMÚDEZ, F. L. 2010. Produção Agrícola Intensiva de Regadio. Land Care in Desertification Affected Areas. Fascículo C (3): s.p.

HARE, F. K et al. 1992. Desertificação: causas e consequências. Lisboa, Fundação Calouste Gulbenkian.

KOSMAS, C.; YASSOGLOU, N.; KOUNALAKI, A.; KAIRIS, O. 2010. Abandono da Terra. Land Care in Desertification Affected Areas. Fascículo B (4): s.p.

LOBÃO, J. S. B.; SILVA, B. C. N. 2013. Análise socioambiental na região semiárida da Bahia: geoprocessamento como subsídio ao ordenamento territorial. Feira de Santana, UEFS.

MATALLO JUNIOR, H. 2001. Indicadores de desertificação: histórico e perspectiva. Brasília, DF, UNESCO.

NATIONAL AERONAUTICS AND SPACE ADMINISTRATION - NASA. 2013. Modelo digital de terreno (MDT). Homepage: https://gdex.cr.usgs.gov/gdex/.

NASCIMENTO, F. R. 2013. O fenômeno da desertificação. Goiânia, UFG.

OLIVEIRA JUNIOR, I. 2014. O processo de desertificação: a vulnerabilidade e a degradação ambiental no polo regional de Jeremoabo - Bahia. Universidade Federal da Bahia, Salvador, Dissertação.

QUARANTA, G. Agricultura de Sequeiro. Land Care in Desertification Affected Areas. Fascículo C (4): s.p.

SISTEMA DE INFORMAÇÃO GEOREFERENCIADAS - SIG-BAHIA Sistema de Informações sobre Recursos Hídricos - SIRH. Salvador: Superintendência de Recursos Hídricos, 2003. 2 CD - Rom.

TRICART, J. 1997. Ecodinâmica. Rio de Janeiro, IBGE.

UNITED NATIONS CONVENTION TO COMBAT DESERTIFICATION - UNCCD. 1997. Convenção das Nações Unidas de combate à desertificação nos países afetados por seca grave elou desertificação, particularmente na África. Brasília, DF: MMA. VALENTIN, C.; POESEN, J.; YONG LI. 2005. Gully erosion: Impacts, factors and control. Catena. (63): 132-15. 